\title{
Usos públicos da história: origens do debate e desdobramentos no ensino de história
}

\author{
Public uses of History: Origins of the debate \\ and developments in History teaching
}

Ana Lima Kallás*

\section{Resumo}

$\mathrm{O}$ artigo tem como objetivo discutir o boom dos usos públicos da história nas sociedades contemporâneas. Busca apresentar a origem histórica da expressão, localizada na "querela entre historiadores" na Alemanha acerca do nazismo, bem como as mudanças e desenvolvimento que a expressão sofreu, ultrapassando o marco espacial e de significação originais. Aborda três casos em que se destacam os usos públicos da história, a saber, os revisionismos históricos, a história pública e o ensino de história. Os três campos, apesar de suas singularidades, mantêm interfaces com a memória, interagindo permanentemente entre si e contribuindo para forjar sentidos de passado na contemporaneidade. Constituem, portanto, espaços fundamentais de disputa de hegemonia, podendo servir para reforçar a passividade ou para construir olhares transformadores.

Palavras-chave: usos públicos da história; ensino de história; hegemonia.

\section{Abstract}

This article aims to discuss the boom of public uses of history in contemporary societies. In order to do so, it seeks to present the historical origin of the expression, which is situated in the "Historians dispute" in Germany about Nazism, as well as the changes it underwent and its further development beyond the original space and meaning frames. Furthermore, the article tries to address three fields that highlight the public uses of history, namely, historical revisionism, public history and history teaching. Despite their singularities, all three interfaces with memory, interact permanently with one other and contribute to forge meanings of the past in contemporaneity. Therefore, they are key in the struggle for hegemony, serving either to reinforce passivity or to build transforming practices.

Keywords: public uses of history; History teaching; hegemony.

\footnotetext{
* Doutoranda em História pela Universidade Federal Fluminense (UFF), mestre em História Social pela Universidade Federal do Rio de Janeiro (UFRJ). Bolsista CNPq. Rio de Janeiro, RJ, Brasil. analimakallas@gmail.com
} 
As origens do debate sobre "usos públicos da história" mostram-se relevantes para reflexões atuais, em especial para os estudos que tratam dos revisionismos históricos, da história pública e do ensino de história. Este artigo irá discorrer, em um primeiro momento, sobre o sentido que o termo adquiriu naquele contexto histórico, a saber, na "querela entre historiadores" que ganhou espaço na Alemanha Ocidental em torno da temática do nazismo e do Holocausto.

O conceito foi usado pelo filósofo alemão Jürgen Habermas e vincula-se à noção de "esfera pública" por ele desenvolvida em fins da década de $1950 \mathrm{e}$ início da seguinte. A partir daí, o termo ganhou certa popularidade e passou a ser adotado por diversos historiadores, principalmente europeus, ganhando sentido mais amplo e complexo. Seu emprego se aproxima de outros conceitos também usados por historiadores brasileiros e latino-americanos, como "cultura histórica", "divulgação histórica" e "história de circulação massiva", ou mesmo dialoga com eles.

Em um segundo momento, abordaremos, de forma breve, três casos em que se destacam os usos públicos da história: os revisionismos históricos, a história pública e o ensino de história. Apesar de suas singularidades, os três se encontram em permanente interação entre si e contribuem para forjar sentidos de passado nas sociedades contemporâneas. Da mesma forma que a produção historiográfica, as representações do passado contidas nesses campos são produzidas a partir das demandas do presente e das disputas políticas, culturais, econômicas e sociais colocadas. Nesse sentido, constituem áreas de disputa, de conflitos intensos, podendo servir para reforçar a passividade ou para construir olhares participativos e transformadores, configurando espaços cada vez mais centrais de disputa de hegemonia na contemporaneidade.

\section{ORIGENS DO DEBATE: USOS PÚBLICOS DA HISTÓRIA E ESFERA PÚBLICA EM HABERMAS}

O termo "uso público da história” foi usado pela primeira vez por Jürgen Habermas na polêmica entre historiadores que teve lugar na República Federal da Alemanha em 1986 e 1987. A "querela" (Historikerstreit) se deu a partir da publicação de um artigo de Ernst Nolte (1923-2016) no jornal Frankfurter Allgemeine Zeitung (FAZ), no qual defendia sua tese sobre o nazismo, 
afirmando que tanto o nazismo quanto o Holocausto foram "cópias do bolchevismo", aproximando o "extermínio de classe" dos bolcheviques do "extermínio de raça" dos nazistas. Segundo Nolte, diante de tantos massacres em massa no século XX, tais como os realizados pelos Estados Unidos no Vietnã e o Gulag soviético, os alemães ocidentais deveriam ficar "em paz consigo mesmos" e deixar o "passado passar". ${ }^{1}$ Nesse contexto, o filósofo Habermas publicou uma crítica no semanário Die Zeit, denunciando as "tendências apologéticas" do artigo de Nolte e da historiografia produzida por autores como Michael Stürmer e Andreas Hillgruber, cujo propósito comum era o de normalizar o nazismo e o Holocausto na identidade histórica alemã. Segundo Habermas,

Os planejadores ideológicos querem criar consenso em torno de um renascimento da consciência nacional, mas ao mesmo tempo têm de eliminar as imagens de Estado nacional hostil no âmbito da Otan. A teoria de Nolte oferece uma grande vantagem para essa manipulação. Ela mata dois coelhos com uma só cajadada: os crimes nazistas perdem sua singularidade porque podem ser compreendidos, no mínimo, como respostas às ameaças de extermínio (que persistem até hoje) por parte dos bolcheviques. Auschwitz reduz-se ao formato de uma inovação técnica e explica-se a partir de uma ameaça 'asiática' de um inimigo que continua à nossa porta. (Habermas, 1989, p.25)

Em 1997, Habermas foi convidado pelos editores da revista Cadernos de Política Alemã e Internacional (Blätter für deutsche und internationale Politik) a pronunciar-se sobre a obra Os carrascos voluntários de Hitler, do autor escolhido para o prêmio Democracia, o historiador Daniel J. Goldhagen. A tese de Goldhagen, segundo a qual o genocídio produzido pelos nacional-socialistas alemães representou uma ação antissemita há muito tempo arraigada em parte da população alemã, provocou nova polêmica entre historiadores, principalmente entre aqueles que se opunham a qualquer tipo de normalização do nazismo. Em função disso, esperava-se, com grande expectativa, o discurso de Habermas, pronunciado em 10 de março de 1997.

Para o professor da Universidade de Frankfurt, o livro de Goldhagen teria dado novo impulso à reflexão sobre o uso público da história, já que trazia à tona uma interpretação inovadora acerca do nazismo, apontando o engajamento de alemães comuns na lógica de extermínio nazista. Habermas defendeu então que 
a função do historiador não deveria ser pautada pelo interesse do grande público, formado, em sua maioria, por participantes do próprio passado nazista em busca de autocompreensão e localização histórica. O filósofo apontou a diferença entre o historiador e o juiz, afirmando que o uso público legítimo da história, diferentemente dos discursos morais e legais, não deveria culpar ou inocentar antecedentes, mas garantir explicações históricas que assegurassem a consciência crítica das novas gerações. A obra de Goldhagen teria ampliado um debate que até então ficara restrito ao âmbito dos historiadores, filósofos e sociólogos alemães - especialistas no estudo do nacional-socialismo e do fascismo -, pois rompia tanto com as explicações revisionistas de Nolte e outros pesquisadores, quanto com as explicações que buscavam responsabilizar apenas Hitler e seu grupo mais próximo pelo genocídio e prática antissemita, como um "desvio de conduta" ou "patologização".

A partir desse novo patamar de discussão pública, seria possível conciliar autocompreensão política e consciência histórica. Dado que o conceito de "crime contra a humanidade" foi originado de uma experiência alemã, seria necessário que as novas gerações compreendessem seu passado. Conhecer as tradições que levaram à formação do antissemitismo na Alemanha não seria o mesmo que defender a imputação de uma culpa coletiva aos alemães (Habermas, 1997).

A posição de Habermas reforçou a perspectiva defendida por Theodor Adorno e Max Horkheimer cinco décadas antes, quando da publicação de Dialética do Esclarecimento (1944) e depois de Educação após Auschwitz (1969) de autoria de Adorno. Utilizando a concepção de Sigmund Freud em O mal-estar na civilização (1930), Adorno e Horkheimer sublinharam o reforço do aspecto anticivilizatório produzido pela civilização moderna capitalista e a perpetuação da barbárie numa sociedade na qual persistem os elementos do "progresso". Assim, o antissemitismo estaria inscrito no processo civilizatório, seus aspectos teriam acompanhado a "marcha do progresso", que faz uso de ideologias para justificar políticas de dominação. Dessa forma, os autores da Escola de Frankfurt pontuaram que, antes dos judeus, foram perseguidos e exterminados os negros, os pobres, os protestantes, os católicos e os árabes, podendo cada um, ao mesmo tempo, "tomar o lugar do assassino, na mesma volúpia cega do homicídio, tão logo se converta na norma” (Adorno; Horkheimer, 2006, p.142). E concluíram, "não existe nenhum genuíno antissemitismo e, certamente, não há nenhum 
antissemita nato". A perseguição aos judeus, da mesma forma que a perseguição em geral, não pode ser separada da ordem burguesa. Sua essência é a violência que se manifesta no nazismo. Para Adorno, a educação teria, portanto, papel fundamental, devendo se pautar não pelo "fetichismo da técnica", que gera uma "consciência coisificada", mas por uma reflexão crítica sobre Auschwitz e por uma formação que não reprima o medo.

Para a educação, a exigência que Auschwitz não se repita é primordial. Precede de tal modo quaisquer outras, que, creio, não deva sem precise ser justificada. Não consigo entender como tenha merecido tão pouca atenção até hoje. Justificá-la teria algo de monstruoso em face da monstruosidade que ocorreu ... todo debate sobre parâmetros educacionais é nulo e indiferente em face deste - que Auschwitz não se repita. Foi a barbárie, a qual toda educação se opõe. Fala-se da iminente recaída na barbárie. Mas ela não é iminente, Auschwitz é a própria recaída; a barbárie subsistirá enquanto as condições que produziram aquela recaída substancialmente perdurarem. (Adorno, 1986, p.33)

O conceito de uso público da história, tal como utilizado por Habermas, guarda relação com essa concepção apresentada por Adorno, de se defrontar diretamente com o passado traumático, entendendo-o como parte do presente e do próprio princípio de progresso sobre o qual se forjaram as sociedades europeias e norte-americana. O uso público da história teria, à vista disso, uma função pedagógica, com possibilidade transgressora ou conformadora. Essa perspectiva assinala que, apesar da análise pessimista acerca da indústria cultural e dos meios de comunicação de massa na sociedade capitalista contemporânea, Adorno considerava a possibilidade de uma educação transgressora, que pudesse formar cidadãos na contramão da barbárie.

O conceito de uso público da história também se relaciona com o próprio estudo de Habermas sobre o processo de conformação da esfera pública burguesa, tese de pós-doutorado publicada em 1961 e apresentada à Faculdade de Filosofia de Marburg, na Alemanha. Nessa obra, a discussão sobre a categoria de esfera pública é feita a partir de uma análise histórica sobre seu desenvolvimento na Inglaterra, França e Alemanha do século XVII ao XX. Habermas entende a esfera pública como espaço de ideologia e dominação, apesar de também nela identificar potenciais de emancipação. Para ele, a sociedade democrática burguesa contradiz as premissas que estruturam a sua 
autocompreensão, ao criar os próprios obstáculos que impedem a realização dos potenciais de liberdade e direitos.

Partindo da ideia kantiana de "uso público da razão", ${ }^{2}$ Habermas discorre sobre a formação de uma esfera pública desde a Grécia Antiga e o espaço da polis como possibilidade de interação entre livres e iguais, passando pela formação do Estado moderno até a sociedade de massas no capitalismo monopolista. Na Europa moderna, os primórdios de uma esfera pública estariam nos cafés e salões, espaços de sociabilidade, onde eruditos e proprietários se reuniam para discutir assuntos de interesse geral da sociedade, sem visar, necessariamente, à conquista de poder no Estado.

A expansão dessa esfera pública não fora, no entanto, acompanhada por uma democratização do debate crítico-racional entre indivíduos livres, tal como apontaram os liberais. A discussão pública e a formação de uma opinião pública teriam sido substituídas pela prática da negociação e compromisso de interesses privados. O processo do exercício de poder ocorreria diretamente entre as administrações privadas, as federações, os partidos e a administração pública. O público teria sido incluído nessa circulação de poder apenas com a finalidade de aclamação.

A substituição de um público crítico, que discute cultura mediante razões, por um público consumidor passivo de produtos culturais foi decisiva no processo de despolitização da esfera pública. Os novos meios de comunicação de massa serviriam, cada vez mais, para dar prestígio às autoridades públicas. A esfera pública acabaria transformando a política em espetáculo dirigido, em que os líderes e partidos pretendem, de tempos em tempos, obter uma aclamação plebiscitária de uma população despolitizada. A maioria da população está excluída da discussão pública e dos processos de tomada de decisão. As novas mídias cerceiam as reações do receptor, cativam o público ouvinte, privando-o de falar, contradizer e contra-argumentar.

Assim, na sociedade de massas, a esfera pública assumiria funções de propaganda. "Quanto mais puder ser implementada como médium [meio] de influência política e econômica, tanto mais se torna apolítica no todo e se privatiza em seu aspecto" (Habermas, 2014, p.384). Em resumo, nas democracias contemporâneas teria havido uma ampliação da esfera pública, mas o público mediatizado é solicitado para fins de aclamação. O público está cada vez mais distante do exercício e arranjos do poder, não sendo levado a pensar, 
nem a argumentar. Nesse sentido, a esfera pública, formada por pessoas privadas e pelas organizações da sociedade civil, não constituiria uma dimensão emancipada e de livre acesso, isenta de relações de poder e de interesses particulares, como apontaram Marx e Hegel, autores com quem Habermas dialoga (Habermas, 2014, p.297). A esfera pública burguesa contradiz seu próprio princípio de acessibilidade universal: a opinião pública não passa de uma máscara de interesses particulares de uma classe que tem acesso ao poder público do Estado.

O debate proposto por Habermas também dialoga com a Dialética do Esclarecimento (1947). Nela já constava a ideia de que a produção, a circulação e o impacto das informações não são processos passíveis de serem analisados apenas do ponto de vista da técnica e da linguagem. O desenvolvimento da indústria cultural e dos meios de comunicação de massa teria possibilitado, por um lado, a democratização da informação, e por outro, o avanço da alienação e a restrição da capacidade de reflexão crítica e criativa. Nesse sentido, pensar a produção e a circulação pública de uma produção histórica na sociedade contemporânea capitalista implicaria identificar seu processo de reconstrução (seu conteúdo), seus fins, seu público-alvo e, finalmente, seus impactos.

Se fizéssemos o esforço de relacionar ambos os conceitos tal como desenvolvidos por Habermas, poderíamos sugerir que o uso público da história consiste na veiculação de uma interpretação histórica para um público expandido, que não se resume aos próprios historiadores nem ao âmbito acadêmico. $\mathrm{O}$ uso de uma dada produção historiográfica passaria por um processo de reconstrução e adaptação, a fim de ser lida/vista/sentida por um público mais amplo. Nas sociedades contemporâneas, os usos públicos da história podem ser muitos, diante do avanço dos meios de comunicação de massa, da internet e das tecnologias de informação. Esses usos são feitos a partir de determinados fins, isto é, de certos interesses de ordem individual ou coletiva, e têm efeitos que podem ser, também, diversos: políticos, culturais, econômicos e sociais. Com isso queremos dizer, empregando as contribuições de Habermas e Adorno, que os usos públicos da história não obedecem a critérios de imparcialidade e pura objetividade, mas respondem a demandas sociais ou a interesses políticos e econômicos.

O historiador italiano Nicola Gallerano (2007) buscou apontar as relações de conflito e de convergência entre a história dos historiadores e o uso público 
da história. Segundo ele, a maior parte dos historiadores considera haver uma oposição entre os dois campos, não considerando que a utilidade pública da história é a sua justificativa original, atividade que acaba regulando a relação entre memória e esquecimento, entre o que é “digno" e "não digno" de ser lembrado.

Gallerano define uso público da história como "tudo o que se desenvolve fora dos lugares destinados à investigação científica em sentido estrito, da história dos historiadores, habitualmente escrita por especialistas e para um segmento muito restrito de público" (Gallerano, 2007, p.87).

Nessa definição, diversos campos podem servir como uso público da história, tais como os meios de comunicação, as artes, a literatura, a escola, os museus, os monumentos, os espaços urbanos, as associações culturais, os partidos e os grupos religiosos, étnicos e culturais. Em geral, esses espaços que promovem usos públicos da história o fazem com objetivos políticos (alguns mais, outros menos) e promovem uma leitura polêmica do passado, a partir da memória do respectivo grupo. Outrossim, os políticos profissionais são considerados promovedores de usos públicos da história. Gallerano considera ainda que certos trabalhos científicos podem ter impacto público que transcende o círculo de especialistas, como por exemplo a biografia de Mussolini escrita pelo historiador Renzo De Felice, ou então as publicações de historiadores em meios de comunicação de massa, como foi o caso da "querela entre historiadores”, de caráter público, da qual Habermas participou ao criticar pesquisadores revisionistas com relação à história do nazismo e do Holocausto.

O historiador italiano se aproxima da definição de Habermas quando diferencia a história de seu uso público, porém não os coloca numa relação de oposição completa. Para Habermas, o uso público da história seria marcado pela utilização da "primeira pessoa", com objetivos políticos e pedagógicos explícitos, a saber, construir o consenso acerca de certos valores decisivos para a convivência civil. A história, por sua vez, seria marcada pela produção em "terceira pessoa", que caracteriza o distanciamento do historiador com relação a seu objeto de estudo. Gallerano faz duas considerações a respeito da posição de Habermas.

A primeira diz respeito ao uso público da história pelos meios de comunicação de massa. A discussão acerca dos conflitos político-ideológicos inerentes ao processo de publicização da história, em especial, a que ocorre pelos mass 
media, deve ser considerada não apenas em termos "manipuladores”. Para o historiador italiano, o uso público da história não assume (sempre) um caráter político em sentido estrito e muito menos um uso político frequentemente manipulador. Há usos públicos que oferecem apenas entretenimento e fuga do cotidiano, outros que resgatam identidades individuais e coletivas e podem apresentar um significado distinto com potencial libertador. Em outras palavras, o uso público da história pode ser um terreno de conflitos, de feridas da memória, de silenciamentos ou de clarificação de temas pouco debatidos. Contudo, também pode ser usado para manipulação, para o estabelecimento de analogias anacrônicas etc. Sendo instrumento de crescimento ou de degeneração, sempre pode proporcionar a transformação da consciência coletiva. ${ }^{3}$

A segunda consideração de Gallerano refere-se à perspectiva de história defendida por Habermas, ainda marcada pelas oposições binárias entre história e seus usos públicos, história e memória, objetividade e subjetividade, imparcialidade e parcialidade. No entanto, é importante salientar que, ao analisar a emergência da esfera pública na Europa, Habermas aborda o contexto de configuração do conceito moderno de História. O desenvolvimento do conceito, de acordo com Reinhart Koselleck, teria se dado tanto em discussões científicas, quanto em diálogos político-sociais do cotidiano realizados nos salões e cafés frequentados pela burguesia intelectualizada nos séculos XVIII e XIX. Segundo o historiador alemão, "a gênese do conceito moderno de história coincide com sua função social e política - sem naturalmente se limitar a ela ... Foi justamente o reivindicado caráter científico do conceito de história que reforçou sua força integrativa social e política" (Koselleck, 2013, p.186). Assim, de acordo com Koselleck, quanto mais a história é mobilizada publicamente, tanto mais flexível se apresenta às percepções dos grupos sociais mais variados, aumentando o interesse em abordá-la em sua modalidade escolar.

A utilização política direta da história, que atingia um amplo público de ouvintes e leitores, só foi possível porque a história foi entendida não apenas como ciência do passado, mas sim como espaço de experiência e meio de reflexão da unidade de ação social e política que se tem visto. Koselleck aponta que no século XIX, historiadores alemães, como Johann Droysen, afirmaram que "de modo nenhum" a ciência histórica lidaria 
só com a máscara mortuária dos passados... Compreendendo e compreendido, sua História representa, para eles, uma consciência de si mesmos, uma compreensão de si. Assim, nossa ciência vai conquistando sua posição e sua tarefa naquilo que está surgindo; aquilo que acontece ao nosso redor e conosco não é outra coisa que o presente da História, a História do presente. (Droysen apud Koselleck, 2013, p.190)

No século XIX, Marx, ao escrever o 18 Brumário de Luís Bonaparte, também apresentava uma concepção moderna de história, na qual o passado deveria servir para autodefinição política e social, e para forjar outra perspectiva de futuro. Para Marx, também citado por Koselleck, a revolução social do século XIX não deveria buscar exemplos no passado, apenas no futuro:

Não é do passado, mas unicamente do futuro que a revolução social do século XIX pode colher a sua poesia. Ela não pode começar a dedicar-se a si mesma antes de ter despido toda a superstição que a prende ao passado. As revoluções anteriores tiveram de recorrer a memórias históricas para se insensibilizar em relação ao seu próprio conteúdo. A revolução do século XIX precisa deixar que os mortos enterrem seus mortos, para chegar ao seu próprio conteúdo. Naquelas, a fraseologia superou o conteúdo, nesta, o conteúdo supera a fraseologia. (Marx, 2011, p.28-29)

Assim, o uso diferenciado do passado no século XIX, fosse como exemplo para legitimar uma nova tomada de posição ou para servir de embasamento para uma reivindicação de ruptura, servia para pensar o espaço da experiência política e social e para os prognósticos que podiam oferecer, o horizonte de expectativas.

Na década de 1990, o antropólogo haitiano Michel-Rolph Trouillot (1995) pontuou uma preocupação com o processo de silenciamento do passado e com a disputa de poder existente na produção histórica. Trouillot chamou atenção para a forma pela qual as narrativas sobre o passado são construídas, para além da dicotomia entre processo histórico ("o que aconteceu”) e conhecimento histórico ("o que se diz ter acontecido"). ${ }^{4}$ Entre o "realismo mecânico" e o "construtivismo ingênuo" existiria um aspecto crucial que seria entender como a história é construída. Refletir sobre o processo de construção da história abrange pensar em todas as formas de produção histórica, isto é, seus usos 
públicos e políticos, que impactam e são impactados pela história acadêmica. Os debates sobre a escravidão, o Holocausto e as ditaduras latino-americanas, por exemplo, sugerem que a relevância histórica não deriva diretamente do impacto original do evento, mas da maneira como foi inscrito socialmente. Trata-se de debates que envolvem historiadores profissionais, líderes étnicos e religiosos, militantes políticos, jornalistas, associações da sociedade civil, cidadãos independentes e militantes. Essa variedade de narradores é apenas um dos indicadores de que as teorias da história apresentam uma visão limitada no campo da produção histórica. Elas subestimam o tamanho, a relevância e a complexidade da sobreposição de lugares na qual a história é produzida, notavelmente fora da academia.

Ainda sobre as relações de aproximação, troca, conflito e influência entre história e seus usos públicos, vale ressaltar a contribuição do historiador italiano, estudioso do fascismo, Enzo Traverso. Próximo à perspectiva de Gallerano, Traverso (2007) afirma que o trabalho do historiador contribui para forjar o uso público da história. O historiador de ofício orienta a memória, contribui para a formação de uma consciência histórica, de uma memória coletiva plural e conflitiva. Mas a estrada não é de mão única.

Os debates alemães, italianos e espanhóis sobre o passado fascista, os debates franceses sobre o passado vichysta e colonial, os debates argentinos e chilenos sobre o legado das ditaduras militares, os debates europeus e americanos sobre a escravidão - a lista seria inesgotável -, ultrapassam em muito as fronteiras da busca histórica. Invadem a esfera pública e penetram em nosso presente. (Traverso, 2007, p.37)

Traverso sugere que quanto mais forte é uma memória (e as demandas pelo "dever de memória" são o exemplo mais paradigmático disso), em termos de reconhecimento público, mais o passado é suscetível de ser explorado e elaborado como história. Essa relação não é direta, mas resultado de múltiplas mediações. A história também influencia a memória, já que não existe memória pura original: as lembranças são elaboradas por uma memória inscrita no espaço público, submetidas a modos de pensar coletivos e também influenciados por paradigmas científicos da representação do passado.

História, memória e usos públicos da história constituem, portanto, formas de uso do passado e de relação das sociedades com o passado. Na década 
de 1990, o historiador francês François Hartog (2014) desenvolveu o conceito de regime de historicidade para compreender a conexão de uma sociedade com seu passado. Baseando-se na contribuição de Koselleck, Hartog buscou tratar a assimetria entre experiência e expectativa causada pela sensação de aceleração do tempo a partir da modernidade. O conceito serviria então para pensarmos nossas relações com o tempo, e principalmente os momentos de "crise do tempo", "quando vêm justamente perder sua evidência as articulações do passado, do presente e do futuro" (Hartog, 2014, p.37).

Henry Rousso (2016), comentando o trabalho de Hartog, aponta que o conceito diz respeito ao

modo pelo qual uma sociedade dispõe os quadros culturais que organizam os vieses através dos quais o seu passado a afeta ... o modo pelo qual esse passado é presente no seu presente ... o modo pelo qual ela o cultiva ou o enterra, o reconstrói, o constitui, o mobiliza etc. ... O regime de historicidade definiria uma forma culturalmente delimitada, portanto convencional, de relação com o passado; a historiografia seria uma dessas formas e, enquanto gênero, um elemento sintomático de um regime de historicidade englobante. (Rousso, 2016, p.22)

Rousso, ao pensar sobre a configuração da história do tempo presente, aborda a mudança das sociedades com relação ao seu passado a partir de acontecimentos que geraram importantes rupturas, como a Revolução Francesa, a Revolução Russa e as grandes guerras. Essas fraturas teriam levado a alterações nos regimes de historicidade e a uma transformação da própria escrita da história, que passou a não poder mais ignorar o princípio ético-político. Da mesma forma que Rousso, Kosellek (2013) também apontara para a fratura provocada pela Revolução Francesa na relação passado, presente e futuro e na mudança do conceito de História. O presente passaria a ser percebido como uma transição instável, pela descontinuidade entre o espaço da experiência e o horizonte de expectativa, e o conceito de história deixaria de estar marcado pelo viés teleológico. A mudança no regime de historicidade de uma sociedade teria impactos nas diversas narrativas históricas.

Outro conceito que trata das conexões das sociedades com seu tempo pregresso é o de cultura histórica. Tal conceito, formulado na tradição da historiografia germânica, vem sendo usado por historiadores brasileiros. Segundo Jörn Rüsen (1994), a cultura histórica diz respeito ao papel da memória 
histórica no espaço público, isto é, “à grande atenção suscitada pelos debates acadêmicos fora do círculo especializado e à surpreendente sensibilidade do público no uso de argumentos históricos para fins políticos" (Rüsen, 1994, p.1). Desse modo, a investigação acadêmica, o ensino escolar, a conservação de monumentos e os museus constituiriam estratégias de articulação prática da consciência histórica na vida de uma sociedade. Para o historiador alemão, a cultura histórica abarcaria, portanto, as formas pelas quais uma sociedade lida com suas experiências ao longo do tempo, oferecendo um "húmus" de conhecimento, interpretação e de reprodução da história (Sá, 2016, p.24). Nesse sentido, a experiência histórica não seria dada apenas pelos vestígios do passado, mas pela constituição de nossa identidade ao longo do tempo. Em outro texto, Rüsen (1996, p.100) apontou que "antes de pensarmos em história, e antes de a rememorarmos, já somos história. Antes de pensarmos no passado como passado ... o passado é presente".

No contexto brasileiro, o conceito de cultura histórica foi empregado pela historiadora Ângela de Castro Gomes (2007) para entender como as sociedades lidam com seu passado ao longo do tempo, considerando, para a análise, diversos tipos de narrativas históricas. O estudo de Gomes se concentrou nas formas pelas quais o Estado Novo (1937-1945) no Brasil evocou e incentivou, por meio de políticas públicas, a investigação sobre o passado com fins de consolidar uma identidade nacional. O passado deveria ser enfrentado a fim de construir uma nova "cultura política" baseada na ideia da centralização política, crítica ao liberalismo e às experiências políticas anteriores do Brasil, que consagraram a descentralização e o federalismo. A história, como sinônimo de "passado" e como movimento linear e evolutivo, foi usada pelos representantes do Estado Novo a fim de legitimar a nova política que se queria construir. $^{5}$

Servindo-se do arcabouço teórico da tradição historiográfica alemã, a historiadora brasileira Helenice Rocha (2014) discute o conceito de divulgação histórica como uma das formas de expressão da cultura histórica. A divulgação histórica seria a criação e apropriação de produtos culturais que evocam o passado. Romances, novelas, filmes e representações pictóricas recolhem, do passado, elementos oferecidos pela história e pela memória, que funcionam como moldura referencial para sua expressão. Essa mobilização da história e/ ou da memória atua em favor de determinadas causas e ideologias, compondo 
um campo de disputas. O termo "divulgação histórica", baseado no conceito original de "divulgação científica", acaba, no entanto, mantendo a ideia binária que separa história de seus usos públicos, não fornecendo novos elementos para a compreensão de suas influências mútuas.

\section{USO PÚBLICO DA HISTÓRIA: REVISIONISMOS, HISTÓRIA PÚBLICA E ENSINO DE HISTÓRIA}

Os debates em torno dos usos públicos da história têm ganhado cada vez mais espaço, principalmente nos estudos relativos aos revisionismos com relação ao passado recente, à configuração de uma história pública e ao ensino de história. Os três debates podem convergir e apresentam influências recíprocas. Abordaremos, de maneira breve, como cada um deles tem sido abordado em parte da literatura sobre o tema.

O crescimento excessivo dos usos públicos da história é um fenômeno típico das sociedades altamente mediatizadas de finais do século XX e diz respeito, de acordo com Gallerano, a dois aspectos: (1) o impacto do fim do mundo comunista nas representações políticas e ideológicas em âmbito mundial; e (2) à obsessão memorial, que se encontra na origem de uma percepção social de profundo desamparo quanto às perspectivas de futuro. Nesse contexto, e em estreita conexão com o boom do uso público da história, observa-se, em várias sociedades, a emergência do revisionismo histórico como fenômeno social.

O termo revisionismo pode significar revisão, ou seja, renovação de interpretações com base na crítica a uma perspectiva dominante, a qual é questionada de um ponto de vista inovador. Nessa acepção ampla do termo, todo historiador é revisionista, já que a revisão corresponde a uma tarefa inerente ao trabalho científico, pois o desenvolvimento científico implica uma multiplicidade de modelos teóricos e paradigmas interpretativos, os quais são progressivamente substituídos sempre que a atividade de investigação suscita novos pontos de vista e a consequente adoção de novos pontos de vista. No entanto, para Traverso (2007), as revisões comumente denominadas revisionistas adquirem uma conotação negativa, uma vez que implicam "uma viragem ético-política" na forma de compreender o passado.

A historiadora Luciana Soutelo (2014), utilizando as contribuições teóricas de Traverso e Habermas, aponta: 
Trata-se de tendências apologéticas sobre o passado no que diz respeito a regimes nazifascistas e, de forma ampla, ditaduras de direita do século XX; de releituras que procuram redistribuir o ônus da culpa no que diz respeito a guerras - invertendo-se os juízos social e historiograficamente dominantes de modo a converter os opressores em vítimas -; e de criminalizações de revoluções, movimentos e processos revolucionários e, de forma mais geral, visões do mundo e valores de esquerda. Portanto, segundo Traverso, tais revisões, para além de questionarem uma interpretação dominante, rejeitam uma consciência histórica compartilhada e uma responsabilidade coletiva em relação ao passado - ao inverterem, por exemplo, a perspectiva histórica acerca de vítimas e opressores. (Soutelo, 2014, p.116)

Para Traverso, portanto, os revisionismos constituem releituras da história de teor principalmente ideológico, com pouca base empírica, e apresentam grande penetração nos espaços públicos, tornando-se, às vezes, fenômenos sociais e parte integrante do senso comum. Esses revisionismos adentram a disputa de memória sobre passados controversos. Essas releituras revisionistas de história priorizam acontecimentos considerados fundacionais das sociedades contemporâneas - Revolução Francesa, Revolução Russa, as guerras mundiais, as diversas ditaduras e guerras do século XX -, ultrapassando com isso a qualidade de reinterpretação historiográfica própria de uma época, incidindo sobre visões de mundo e identidades sociais no presente. Nesse sentido, essas revisões transbordam as fronteiras da historiografia, adentrando o campo mais amplo do uso público da história, e penetram na esfera da memória. ${ }^{6}$

Por sua vez, as discussões mais recentes sobre história pública no Brasil têm se debruçado sobre as formas pelas quais as representações do passado circulam no âmbito público para além das universidades. ${ }^{7}$ De acordo com o historiador Daniel Pinha (2016, p.12), “o giro em direção ao que é praticado como história pública surge como sinal de uma preocupação que envolve usos e apropriações da história em uma comunidade de leitores diversa, formada por um público não ambientado ao circuito propriamente intelectual". Estaríamos diante de uma reflexão sobre os meios de divulgação de trabalhos acadêmicos, formas, narrativas ou linguagens com maior poder de alcance, considerando a diversidade do público; e sobre a inserção da pesquisa e do ensino de história no debate contemporâneo, destacando os efeitos que uma produção histórica pode gerar num determinado contexto social. Este segundo aspecto nos parece o mais relevante dessa discussão. 
A história pública, tal como discutida por Jill Liddington (2011), tem sido entendida em oposição à história acadêmica. Sua prática estaria relacionada à "apresentação popular do passado para um leque de audiências - por meio de museus e patrimônios históricos, filmes e ficção histórica”. Ou seja, o estudo da história pública se conecta a "como adquirimos nosso senso de passado por meio da memória e da paisagem, dos arquivos e da arqueologia (e por consequência, é claro, do modo como esses passados são apresentados publicamente)" (Liddington, 2011, p.34).

Refletindo sobre as contribuições já apontadas por Habermas, Gallerano, Traverso e Koselleck, as discussões que envolvem o nascimento de uma história pública estão presentes há muito tempo nos debates dos historiadores, uma vez que desde que a história surgiu enquanto conhecimento disciplinar, ela também apresentou usos públicos com fins e efeitos diversos, inclusive sobre a própria história acadêmica. Desse modo, consideramos que mais importante que entender a história pública como uma modalidade em oposição à história acadêmica, como dois campos homogêneos e também antagônicos, deveríamos discutir suas influências recíprocas, interações e conflitos. Entendê-la apenas como oposição poderia nos levar ao mesmo problema apontado por Peter Burke (1992) com relação à história "vista de baixo", em contraposição à história das elites, ou da cultura popular em contraposição à cultura erudita tal como discutido por Bakhtin (1987), Ginzburg (1987) e Chartier (1988) quando sugeriram os conceitos de circularidade cultural e apropriação cultural, respectivamente.

Analisando a história pública na Grã-Bretanha, Liddington revela parte dessa problemática: “O que está em cena é uma proposta de história pública inclusiva e democrática, com ênfase não na 'compra' do profissionalismo de uns poucos historiadores, mas sim nas muitas pessoas tendo acesso às suas próprias histórias, com os historiadores ajudando a 'devolver às pessoas a sua própria história"” (Liddington, 2011, p.42).

Liddington sugere que a história pública, diferentemente da história acadêmica, teria a tarefa de "dar voz" ou "devolver a história" que é própria aos segmentos recorrentemente excluídos das produções históricas. O objetivo parece pretensioso, e a autodefinição insiste numa lógica binária. Não necessariamente a história produzida nas universidades irá priorizar a história das elites, e a história pública irá enfatizar a história "vista de baixo". A relação 
entre história e história pública nos parece mais complexa que isso. Soma-se a isso o fato de que o caráter "público" dessa modalidade de história apresenta o mesmo sentido definido por Habermas, qual seja, o de produzir um consumo muitas vezes passivo das "exposições" de massa, pois a própria divulgação tende a obedecer a critérios políticos e econômicos.

Beatriz Sarlo (2006, p.17), ao comparar a história acadêmica com a história de circulação massiva, afirma que a segunda, mais do que a primeira, reconhece a sua legitimidade na representação pública de mercado. Os critérios de escolha de temas e formas de abordagem são os de êxito e de adequação ao desejo dos consumidores, ao passo que a história acadêmica se mantém presa a questões de método. Hoje sabemos que as publicações acadêmicas também são em grande parte pautadas por interesses de mercado, mas, ainda assim, em grau inferior às vertentes de história pública.

Nos Estados Unidos, a história pública, como ramo de profissionalização no ensino superior, surgiu a partir de uma preocupação com a empregabilidade dos historiadores que se formavam. O campo abrange um amplo espectro político que vai desde o trabalho com monumentos do capital privado até projetos de base, organizados por agências estatais. Sua diversidade de ações acaba nos dando a sensação de que a história pública, por ser tão vasta e gelatinosa, é também uma área de conflitos e disputas.

O surgimento da história pública como campo institucionalizado também guarda relação com as demandas por tratamento de temas sensíveis e controversos, como a escravidão, o nazismo, o fascismo e as ditaduras militares no Cone Sul, no sentido de possibilitar que tais temas sejam considerados de frente, com o fito de serem compreendidos e não lamentados. De acordo com Sarlo, a história pública ou de circulação massiva tende a ser mais sensível às demandas de "resgate" do passado, já que se orienta em função das crenças de seu público. Essa história pública "recorre a uma fórmula explicativa, um princípio teleológico que assegura origem e causalidade, aplicável a todos os fragmentos do passado, independentemente da pertinência que demonstre para cada um dos fragmentos reais e concretos". É uma história de grandes esquemas explicativos, que oferece mais certezas que hipóteses (Sarlo, 2006, p.15).

Liddington, tal como Sarlo, também dialoga mais diretamente com as problemáticas da sociedade de consumo ao abordar a história pública. Resume as preocupações centrais do historiador público afirmando sua expectativa 
com relação a um consumo ativo e participativo do passado (e não passivo); o cuidado com relação a ofertas comerciais (a história pública deve ir além de meros interesses de mercado); e a preocupação com o rigor crítico da produção histórica.

A história pública tem caráter pedagógico e pode dialogar diretamente com a cultura escolar. Nesse sentido, é igualmente produtora de visões de mundo, de perspectivas de entendimento do passado a partir de demandas do presente. Contribui para a construção de identidades e ações individuais e coletivas no presente, principalmente para as novas gerações. É aqui que entra o papel dessa história como importante espaço de construção e disputa de hegemonia das representações do passado para ações no presente. A disputa de hegemonia operada pelos usos públicos da história relaciona perspectivas que interligam passado-presente e futuro, pois ao contribuir para que o sujeito se localize historicamente, mobilizando sua consciência histórica, também possibilita que ele construa uma perspectiva de futuro.

A discussão em torno da "função pedagógica" da história esteve presente desde seu nascimento. A história como "mestra da vida", tal como entendida pelos historiadores da antiguidade, tratava das "ações, dos episódios, dos destinos sobre os quais cabia meditar (a partir dos quais se podia aprender algo para a ação política - mas também para os sofrimentos...)” (Meier, 2013, p.50). Esse conceito de história se referia à história como exemplo, como objeto de ensino. Após a Revolução Francesa, o conceito passa a ser entendido além de sua função exemplar para as ações políticas do presente. Para Hegel, a história contribuiria para que as sociedades compreendessem a si mesmas, possibilitando a sua conscientização histórica (Günther, 2013, p.113). Mas essa mudança não impedia as manipulações. Segundo Koselleck, foi no contexto de maior organização social e política das classes subalternas que o papel do ensino de história mais cresceu. Tanto na revolução quanto na restauração, houve uma disputa acirrada em torno do que deveria ser ensinado, e o ensino de história foi defendido por argumentos bastante contraditórios. Em suma, a função do ensino, um uso público da história, esteve presente desde seus primórdios, fundida ao próprio conceito de História. As controvérsias derivaram, portanto, do que e como ensinar, em especial, para as grandes massas.

Jörn Rüsen (2001), ao desenvolver os fundamentos da ciência histórica, aponta para a indissociabilidade entre a história enquanto ciência e seu uso na 
vida prática. Todo processo de formação histórica, em suas múltiplas possibilidades, corresponderia ao atendimento de demandas de orientação existencial e de orientação do ser humano no tempo. O ensino de história nas escolas, os impactos dos meios de comunicação de massa sobre a consciência histórica e como fator da vida humana prática, o papel da história na formação dos adultos como influente sobre a vida cotidiana constitui, segundo Rüsen, "formação histórica". O desenvolvimento da consciência história estaria, portanto, vinculado ao processo de constituição da identidade do sujeito, na medida em que estimularia a elaboração de um sentido histórico para a experiência da evolução temporal de si mesmo e do mundo a partir do desenvolvimento de uma narrativa histórica. Nesse movimento, a lembrança torna presente o passado mediante o movimento da narrativa, e o passado é relacionado ao presente, possibilitando a construção de uma perspectiva de futuro. A narrativa histórica seria, portanto, a atividade intelectual que relaciona presente e passado, permitindo que o presente seja extrapolado em uma perspectiva de futuro. Nesse sentido, a consciência histórica engloba uma análise crítica dos diversos usos públicos da história e de sua implicação na identidade do sujeito. Por isso, o aprendizado da história nas escolas deve abarcar a utilização de interpretações históricas na orientação da vida prática. $\mathrm{O}$ aprendizado a partir do contato com experiências do passado se daria, de acordo com o estudioso alemão, por meio de três operações distintas, mas que caminham juntas: experiência, interpretação e orientação. Na primeira, o estudante amplia seu contato com o passado humano; na segunda, ele aprende a interpretar historicamente essas experiências passadas; e, na terceira, ele aprende a utilizar interpretações históricas na vida cotidiana. Nessa terceira operação estaria o desenvolvimento da capacidade de analisar criticamente diversos usos públicos da história e de identificar os elementos de "tradição" presentes nas narrativas sobre o passado, fator que veremos mais adiante.

Para o autor, a própria teoria da história é também uma didática, uma teoria do aprendizado histórico, transpondo "a pretensão de racionalidade que o pensamento histórico, em sua cientificidade, possui para o enraizamento da história como ciência na vida prática" (Rüsen, 2001, p.49).

Pesquisas atuais no campo do ensino de história têm destacado a questão do "letramento em história", campo de pesquisa pensado a partir do conceito de "consciência histórica" de Rüsen. ${ }^{8}$ O letramento ultrapassaria o desenvolvimento da leitura e da compreensão linguística. Igualmente, superaria a ideia de que o 
aprendizado da história deve se limitar à aquisição do conhecimento histórico como uma série de fatos objetivos. Diferentemente, o letramento em história deveria estimular a mobilização de conhecimentos prévios ao longo da leitura de uma narrativa histórica, estabelecendo uma orientação temporal e permitindo a construção de novos significados para o sujeito que lê. Como uma das funções principais do ensino de história no Brasil, cuja expansão da escolarização não foi acompanhada pela expansão da qualidade da educação, o letramento em história permite a superação da perspectiva binária no que tange à produção e aos impactos produzidos pela história e seus usos.

No debate sobre a formação histórica (ou letramento histórico) é importante pensar a respeito da "tradição", conceito usado por Rüsen, que o associa ao processo de aprendizagem da história, e por Raymond Williams (1988), que o analisa a partir do processo de construção da hegemonia. Para Rüsen, a tradição é formada por elementos do passado que orientam o agir humano, mas nem sempre são interpretados historicamente. Por isso, a atividade da consciência histórica deve trabalhar com os aspectos da tradição, desconstruindo-os, tornando o passado passível de interpretação e reflexão. Nem todo passado é história, da mesma forma que a consciência do passado não é consciência histórica, pois para isso é necessário relacionar o passado ao presente e projetar o futuro. Raymond Williams, por sua vez, considera que a tradição compõe um aspecto central da construção da hegemonia nas sociedades contemporâneas, pois mais do que uma "reminiscência do passado", ela é a expressão de uma profunda incorporação de sentido. A tradição é uma versão seletiva do passado e de um presente em construção. Trata-se, portanto, de um aspecto da organização social e cultural contemporânea, que utiliza uma versão do passado para se conectar ao presente e ratificá-lo, oferecendo-lhe um sentido de continuidade. A tradição, para Williams, pode atuar na legitimação cultural e histórica da ordem contemporânea. ${ }^{9}$

Em 1940, Walter Benjamin apontou, nas teses sobre o conceito de história, que o narrador ou o historiador deveria trazer à tona aquilo que a tradição, oficial ou dominante, não recorda. O ofício do historiador e o resultado de seu trabalho não teriam como função apresentar o passado tal "como ele de fato foi”, mas articulá-lo historicamente, por meio de uma seleção e de um método crítico, apropriando-se de uma "reminiscência", de um rastro pouco ou nada lembrado. Benjamin defende, tal como Marc Bloch em 1949, o esforço de 
compreensão do presente pelo passado e do passado pelo presente. Para Bloch, "a incompreensão do presente nasce fatalmente da ignorância do passado. Mas talvez não seja menos vão esgotar-se em compreender o passado se nada se sabe do presente" (Bloch, 2001, p.65).

Dessa forma, Benjamin e Bloch, Rüsen e Williams, cada um em seu contexto, mostram uma história (que só tem sentido em seus usos públicos), que não se caracteriza mais por heranças e tradições a transmitir, mas por problemas a gerir. Tais problemas devem ser conduzidos a partir de um constante trabalho de "luto" ou de memória a "empreender", haja vista o enraizamento da ideia de que o passado deve ser arrebatado do limbo do esquecimento.

\section{CONSIDERAÇÕES FINAIS}

Neste artigo, buscamos expor as origens do debate em torno do conceito de "usos públicos da história" visto que hoje assistimos a um boom de representações do passado, por meio da memória e da história. A origem do termo chama a atenção para as contendas político-ideológicas nas quais a história é usada para legitimar uma ou outra visão de mundo. A maior ou menor visibilidade social de alguns usos públicos da história se relaciona com as políticas públicas de educação e memória existentes; a força das demandas sociais e de como as sociedades lidam com seus passados; o grau de monopolização dos meios de comunicação e do ramo editorial; em suma, com aspectos que podem produzir passividade e resignação ou reflexão crítica e participativa. Analisar os usos públicos da história é, portanto, refletir sobre um terreno de disputas e conflitos, de construção hegemônica e contra-hegemônica que ultrapassa o âmbito dos Estados-nação, assumindo contornos transnacionais.

Procuramos mostrar que mais importante do que distinguir história e seus usos públicos, colocando-os em campos opostos, é analisar suas influências recíprocas, suas interações e conflitos. Um dos grandes desafios a serem enfrentados diz respeito aos significados e efeitos desses usos no presente e no futuro. Em que pesem as temáticas "sensíveis", tais como o Holocausto, a escravidão negra e as ditaduras civil-militares do século XX, essa questão ganha ainda maior importância, já que nesses casos adentramos em acirradas disputas de memória, em discussões sobre reparação, verdade e justiça. Como apontou Habermas, não cabe aos historiadores julgar o passado, mas possibilitar 
um amplo debate sobre o sentido histórico desses episódios com marcas profundas em nossas sociedades de hoje, principalmente para as gerações que não os viveram diretamente. A abordagem dos temas controversos em sala de aula e em outros espaços públicos segue sendo um desafio no que se refere ao uso do princípio de responsabilidade de forma não binária.

A formação histórica em sua função de orientação no tempo e de mobilização da consciência histórica permite uma desconstrução do presentismo ou desmemória. Sobre presentismo, nos referimos a um problema trazido por Walter Benjamin (2012) já em fins da Primeira Guerra Mundial, que remonta ao fim da experiência transmitida, só nos restando a experiência vivida, que é individual, frágil e efêmera. Estaríamos numa sociedade sem referências, desfigurada pela violência e atomizada por um sistema social que apaga as tradições e fragmenta as existências (Rosas, 2016, p.60). As gerações mais jovens vivem o agora como se não tivesse existido um passado, não aprendem com a experiência das gerações anteriores. Benjamin referia-se a uma pobreza não em experiências privadas, mas em experiências de humanidade. Surge assim uma nova barbárie, que impede a reinvenção crítica do presente.

O historiador português Fernando Rosas (2016) usa o termo desmemória para tratar de uma das formas de manipulação da memória nos séculos XX e XXI: a criação pela mídia, pela escola, pela indústria do entretenimento e pelas redes sociais de um ambiente de "presente contínuo", uma vida cotidiana sem qualquer relação orgânica com o passado público da época atual. Essa situação seria resultado do apagamento de processos históricos "que transportem do passado um potencial subversor da nova ordem". O pensamento hegemônico conservador constrói-se, nessa modalidade, "de silêncios e omissões geradores de um senso comum privado da faculdade de conhecer e comparar e que vai sendo insensivelmente imposto pela generalização da capacidade de reagir" (Rosas, 2016, p.68).

Parece que hoje vivemos sob um grande paradoxo marcado pelo boom de representações do passado pelos diversos usos públicos da história e pela sensação de presentismo, que leva a uma naturalização de uma vida movida pelo individualismo e pelo desejo de consumo desenfreado, na qual o passado é utilizado de forma seletiva, oferecendo uma reificação da ordem contemporânea, tal como sugeriu Williams (1988, p.138). Nesse processo contraditório, as escolas (e particularmente o ensino de história) e os meios de comunicação de 
massa (incluindo as redes sociais) constituem os locais onde são elaborados diversos usos públicos da história. Neles é produzido e reproduzido "um corpo de práticas e expectativas presentes na totalidade da vida: nosso sentido de vida, as percepções que temos de nós mesmos e do mundo em que vivemos. Trata-se de um sistema vivo de significados e valores, fundamentais e constitutivos" (Williams, 1988, p.131). Nesse sentido, os processos educativos e, especialmente, de formação histórica constituem processos centrais de construção da hegemonia, pois criam um sentido de realidade para a maioria das pessoas a partir do que elas mesmas experimentam. ${ }^{10}$ Esse processo dinâmico e vivo pode produzir subordinação e dominação, principalmente em sociedades com desigualdades de meios para realizar escolhas. Mas também pode produzir resistência, hegemonia alternativa ou contra-hegemonia, assumindo formas não necessariamente "políticas" e "econômicas" stricto sensu.

Assim como Adorno, Horkheimer, Habermas e Benjamin estão preocupados com o tratamento a ser dado ao passado recente e à barbárie advinda com a civilização ocidental moderna nos usos públicos da história, Fernando Rosas, Enzo Traverso e Luciana Soutelo estão voltados para análises críticas acerca das representações do passado recente com fins de legitimação de uma ordem neoliberal advinda com a queda do socialismo real. Dentre as potencialidades surgidas com a aceleração dos usos públicos da história está, portanto, a possibilidade de se contrapor à naturalização e à legitimação de uma nova ordem conservadora, nascente em fins da década de 1980, que disputa os conteúdos das representações do passado, sobretudo do passado recente, para "fundar ou refundar as legitimidades ideológicas e políticas do presente e do futuro" (Rosas, 2016, p.48). Dessa maneira, as diversas narrativas históricas, em sua possibilidade de desnaturalização do presente, também têm o potencial de reinventá-lo criticamente, atuando na construção daquilo que Koselleck denominou como um novo "horizonte de expectativas para o futuro".

\section{REFERÊNCIAS}

ADORNO, Theodor. Educação após Auschwitz. In: COHN, Gabriel (Org.) Theodor Adorno: sociologia. São Paulo: Ática, 1986. p.33-45.

.; HORKHEIMER, Max. Dialética do esclarecimento: fragmentos filosóficos. Trad. Guido Antonio de Almeida. Rio de Janeiro: Zahar, 2006. 
BAKHTIN, Mikhail. A cultura popular na Idade Média e no Renascimento: entre práticas e representações. São Paulo: Hucitec; Brasília: Ed. UnB, 1987.

BENJAMIN, Walter. Experiência e pobreza. In: . Magia e técnica, arte e politica: ensaios sobre literatura e história da cultura. (Obras Escolhidas, v.1). Trad. Sérgio Paulo Rouanet. 8.ed. São Paulo: Brasiliense, 2012. p.123-128.

. O narrador. In: . Magia e técnica, arte e política: ensaios sobre literatura e história da cultura. (Obras Escolhidas, v.1). Trad. Sérgio Paulo Rouanet. 8.ed. São Paulo: Brasiliense, 2012a. p.213-240.

Sobre o conceito de história. In: Magia e técnica, arte e política: ensaios sobre literatura e história da cultura. (Obras Escolhidas, v.1). Trad. Sérgio Paulo Rouanet. 8.ed. São Paulo: Brasiliense, 2012b. p.222-234.

BLOCH, Marc. Apologia da história ou o ofício do historiador. Rio de Janeiro: Zahar, 2001.

BURKE, Peter (Org.) A Escrita da História: novas perspectivas. São Paulo: Ed. Unesp, 1992.

CHARTIER, Roger. Textos, impressões e leituras. In: . A história cultural: entre práticas e representações. Lisboa: Difel, 1988.

DURKHEIM, Émile. Da divisão do trabalho social. Trad. Eduardo Brandão. São Paulo: Martins Fontes, 2010.

GAGNEBIN, Jeanne. Lembrar, escrever, esquecer. São Paulo: Ed. 34, 2006.

GAllerANO, Nicola. Historia y uso público de la historia. Pasajes: Revista de Pensamiento Contemporáneo, Valencia (España), n.24, p.87-97, 2007. Disponível em: www.roderic.uv.es; Acesso em: 2 fev. 2017.

GINZBURG, Carlo. O queijo e os vermes: o cotidiano e as ideias de um moleiro perseguido pela Inquisição. São Paulo: Companhia das Letras, 1987.

GOMES, Ângela de Castro. Cultura Política e Cultura histórica no Estado Novo. In: ABREU, Martha; SOIHET, Rachel; GONTIJO, Raquel (Org.) Cultura politica e leituras do passado. Rio de Janeiro: Civilização Brasileira; Faperj, 2007. p.43-63.

HABERMAS, Jürgen. A história é parte de nós. Por que se concedeu o prêmio da democracia a Daniel J. Goldhagen? Textos de história, Brasília, v.5, n.1, p.127-133, 1997.

- Mudança estrutural da esfera pública: investigações sobre uma categoria da sociedade burguesa. Trad. Denilson Luís Werle. São Paulo: Ed. Unesp, 2014.

. Tendências apologéticas. Trad. Márcio Suzuki. Novos Estudos Cebrap, n.25, p.16-27, out. 1989. 
HARTOG, François. Regimes de historicidade: presentismo e experiências do tempo. Trad. Andréa S. de Menezes, Bruna Breffart, Camila R. Moraes, Maria Cristina de A. Silva e Maria Helena Martins. Belo Horizonte: Autêntica, 2014.

HUYSSEN, Andreas. Culturas do passado-presente: modernismos, artes visuais, políticas da memória. Rio de Janeiro: Contraponto; MAR, 2014.

KANT, Immanuel. Resposta à questão: o que é Esclarecimento? Trad. Márcio Pugliesi. Cognitio, São Paulo, v.3, n.1, p.145-154, jan./jun. 2012.

KOSELLECK, Reinhart; MEIER, Christian; GÜNTHER, Horst; ENGELS, Odilo. $O$ conceito de história. Belo Horizonte: Autêntica, 2013.

LIDDINGTON, Jill. O que é história pública? Os públicos e seus passados. In: ALMEIDA, Juniele; ROVAI, Marta Gouveia (Org.) Introdução à História Pública. São Paulo: Letra e Voz, 2011. p.31-52.

.; DITCHFIELD, Simon. Public History: a Critical Bibliography. Oral History, London, v.33, p.40-45, 2005.

MARX, Karl. O 18 de Brumário de Luís Bonaparte. Trad. Nélio Schneider. São Paulo: Boitempo, 2011.

MELO, Demian Bezerra (Org.) A miséria da historiografia: uma crítica ao revisionismo contemporâneo. Rio de Janeiro: Consequência, 2014.

. Revisão e revisionismo historiográfico: os embates sobre o passado e as disputas políticas contemporâneas. Marx e o marxismo, Niterói: UFF, v.1, n.1, jul./ dez. 2013. p.49-74. Disponível em: http://niepmarx.com.br/revistadoniep/index. php/MM/article/download/11/7; Acesso em: 14 dez. 2016.

PINHA, Daniel. Ampliação e veto ao debate público na escola: história pública, ensino de história e o projeto 'Escola Sem Partido'. Revista Transversos, Rio de Janeiro, v.7, n.7, p.11-34, set. 2016.

ROCHA, Helenice. A escrita como condição para o ensino e a aprendizagem de história. Revista Brasileira de História, São Paulo, v.30, n.60, p.121-142, 2010.

. A presença do passado na aula de história. In: MAGALHÃES, Marcelo et al. (Org.) Ensino de história: usos do passado, memória e mídia. Rio de Janeiro: Ed. FGV, 2014. p.33-52.

ROSAS, Fernando. História, (des)memória e hegemonia. In: LOPES, Maria Helena T;; TRINDADE, Luís; LOUÇÃ, Francisco; ROSAS, Fernando (Org.) História e memória: "última lição" de Fernando Rosas (Cerimônia de jubilação de Fernando Rosas). Lisboa: Autores e edições tinta-da-china, 2016. p.41-81.

ROUSSO, Henry. A última catástrofe: a história, o presente, o contemporâneo. Trad. Fernando Coelho e Fabrício Coelho. Rio de Janeiro: Ed. FGV, 2016.

ROVAI, Marta. A pedra que arde: o direito à memória contra a sedução do esquecimento. Seculum - Revista de História, João Pessoa, n.23, p.11-17, jul./dez. 2010. 
RÜSEN, Jörn. Narratividade e objetividade nas ciências históricas. Textos de História, Brasília, v.4, n.1, p.75-102, 1996.

- ¿Qué es la cultura histórica? Reflexiones sobre una nueva manera de abordar la historia. Culturahistórica. (Original: FÜSSMANN, K.; GRÜTTER; H. T.; RÜSEN, J. (Ed.) Historische Faszination. Geschichtskultur heute. Keulen, Weimar y Wenen: Böhlau, 1994. p.3-26). Disponível em: www.culturahistorica.es; Acesso em: 3 fev. 2017.

Razão Histórica: teoria da história: os fundamentos da ciência histórica. Trad. Estevão de Rezende Martins. Brasília: Ed. UnB, 2001.

SÁ, Patrícia Teixeira de. Conhecimento histórico e mídia em uma escola da rede municipal de ensino do Rio de Janeiro. Tese (Doutorado em Educação) - Centro de Teologia e Ciências Humanas, Pontifícia Universidade Católica do Rio de Janeiro (PUC-RJ). Rio de Janeiro, 2016.

SARLO, Beatriz. Tiempo Pasado: cultura de la memoria y giro subjetivo. Una discusión. México, DF: Siglo XXI Ed., 2006.

SILVA, Marco Antônio. Letramento no Ensino de História. Cadernos de História, Belo Horizonte, v.12, n.17, p.111-130, $2^{\circ}$ sem. 2011.

SILVA, Vitória Rodrigues. Estratégias de leitura e competência leitora: contribuições para a prática de ensino em História. História, v.23, n.1-2, p.69-83, 2004.

SOARES, Magda Becker. Letramento: um tema em três gêneros. Belo Horizonte: Autêntica, 1998.

SOUTELO, Luciana. A memória pública sobre a Revolução e a ditadura em Portugal: da valorização do antifascismo ao desenvolvimento do revisionismo histórico. In: LUÍS, Rita; SOUTELO, Luciana; SILVA, Carla Luciana (Org.) A revolução de 197475: repercussão na imprensa internacional e memória(s). Instituto de História Contemporânea: Lisboa, 2014. p.114-127.

TRAVERSO, Enzo. El pasado - Instrucciones de uso: historia, memoria, política. Madrid: Marcial Pons, 2007.

TROUILLOT, Michel-Rolph. Silencing the past: Power and the production of History. Boston: Beacon Press, 1995.

WILLIAMS, Raymond. Marxismo y Literatura. Trad. Pablo di Masso. Barcelona: Península, 1988.

\section{NOTAS}

${ }^{1}$ Em seu livro publicado em 1986, "O passado que não quer passar", Nolte defendia a tese de que entre 1917 e 1945 teria havido uma longa guerra civil europeia, uma espécie de 
atualização da Guerra dos Trinta Anos, provocada e motivada pelo bolchevismo. Sua tese foi duramente criticada pelo filósofo Jürgen Habermas, que usou o termo "revisionista" para qualificá-la (MELO, 2013).

${ }^{2}$ Em 1784, ao tentar conceituar a noção de "Esclarecimento", posteriormente desenvolvida por Adorno, Immanuel Kant apontou que o uso público da razão ocorreria apenas em condições de liberdade e permitiria a realização do esclarecimento entre os homens. Como afirmou Kant, "entendo por uso público de sua própria razão aquele que qualquer homem, enquanto estudioso, realiza diante de todo o mundo letrado" (p.147). O esclarecimento seria, para o filósofo prussiano, a "libertação do homem de sua imaturidade autoimposta", ou seja, tornar-se capaz de empregar seu próprio entendimento, suas próprias ideias, sem a orientação de outro (KANT, 2012).

${ }^{3}$ Utilizamos o conceito de "consciência coletiva" tal como utilizado por Gallerano, que o trata de maneira histórica, considerando que as crenças que conformam uma consciência coletiva se transformam ao longo do tempo, já que a própria forma como uma sociedade considera seu passado e se autodefine também se altera historicamente. Originalmente, o conceito foi desenvolvido pelo sociólogo francês Émile Durkheim para designar "o conjunto de crenças e dos sentimentos comuns à média dos membros de uma mesma sociedade". Essas crenças conformariam um sistema com "vida própria" (DURKHEIM, 2010, p.50).

${ }^{4}$ Troillot se refere a um processo analisado por Koselleck na configuração do conceito de História. Seu significado só teria se consolidado no último terço do século XVIII, com dois processos de longa duração: a criação do coletivo singular, que reúne a soma de histórias individuais em um único conceito; e a fusão de História (conjunto de acontecimentos) e Histoire (narrativa dos acontecimentos).

${ }^{5} \mathrm{O}$ uso do conceito de "cultura histórica" por historiadores brasileiros deve levar em conta as diferenças de tradições historiográficas entre o Brasil e os países da Europa, em especial a Alemanha, onde tal conceito foi forjado. Aqui não poderemos nos aprofundar nessas diferenças, mas entendemos que o uso de tal conceito, tanto aqui quanto na Alemanha, tenta superar o binarismo entre história e seus usos públicos, buscando relações de identidade entre diversas formas de representação do passado numa determinada conjuntura histórica. Ângela de Castro Gomes aponta que nas décadas de 1930 e 1940, mais do que obras historiográficas, proliferaram discursos e práticas sobre um passado e uma história nacionais, que se apropriaram de obras históricas e de narrativas diversificadas que falavam sobre "povo" e "nação". O passado seria parte de uma identidade brasileira que se queria mudar, para a construção do "novo". E o projeto político do Estado Novo se apresentava como a própria encarnação desse "novo". Forjou-se um uso público da história com claros propósitos políticos.

${ }^{6}$ Ao se referir a eventos considerados matriciais para a história do Ocidente, Traverso e outros autores, como Luciana Soutelo, referem-se à Revolução Francesa e à abordagem revisionista de François Furet; ao nazismo e à abordagem revisionista de Ernst Nolte; à Guerra Civil espanhola e à ditadura franquista e sua leitura revisionista presente no Diccionario Español da Real Academia de la Historia; à ditadura salazarista e à revolução 
dos Cravos e à perspectiva revisionista de alguns autores que têm reabilitado a figura de "Salazar", negando o caráter fascista daquele regime e desqualificando o 25 de abril, bem como desconsiderando sua importância na configuração da democracia portuguesa. No Brasil, tal debate tem sido feito pelo historiador Demian Melo, que aponta o viés revisionista de algumas produções historiográficas recentes sobre o golpe de $1964 \mathrm{e}$ a ditadura militar no Brasil, que responsabilizam as esquerdas por seu "deficit democrático". O regime ditatorial pós-1964 no Brasil, segundo determinadas perspectivas, teria sido resultado de uma "reação" à radicalização das esquerdas (cf. MELO, 2014).

${ }^{7}$ Neste artigo, dada a limitação de seu escopo, não tratamos dos campos acadêmicos que mobilizam o conceito de história pública. Fazemos apenas alguns breves comentários críticos, baseados numa reflexão inicial, acerca da forma pela qual o campo da história pública vem sendo configurado no Brasil. O conceito e o debate sobre a importância da História Pública tiveram origem na Inglaterra nos anos 1970, expandindo-se posteriormente para o Canadá, Austrália, Itália, África do Sul e Estados Unidos. A revista History Workshop Journal, publicada em 1976, foi organizada após uma série de oficinas realizadas desde 1967 em Oxford, por Raphael Samuel. Acreditava-se que a história pública seria uma forma de democratização e de reflexão sobre os usos políticos do passado no presente, por meio de uma história feita e narrada pelos grupos tradicionalmente invisibilizados pela história tradicional. Nos Estados Unidos, priorizou-se o debate sobre os usos públicos do conhecimento acadêmico e suas várias formas de narrativas (LIDDINGTON; DITCHFIELD, 2005).

${ }^{8}$ Cf. SILVA, 2011; SOARES, 1998; SILVA, 2004; ROCHA, 2010.

${ }^{9}$ Segundo Raymond Williams, as instituições, como a escola, a igreja e os locais de trabalho reforçam as tradições, pois fornecem o aprendizado de significados, valores e práticas selecionados, pilares da hegemonia. No entanto, nenhuma pressão ou tentativa de adestramento é efetivamente hegemônica. A condição da hegemonia é produzir, constantemente, a efetiva autoidentificação com as formas hegemônicas, uma internalização da dominação na prática social cotidiana. Esse processo, contudo, é pleno de contradições e tensões já que a hegemonia é compreendida como um processo complexo e dinâmico, devendo ser constantemente "renovada, recriada, defendida e modificada" (WILLIAMS, 1988, p.134).

${ }^{10}$ Williams se refere à tradição e às atividades culturais, colocando-as para além da superestrutura e situando-as nos processos básicos de formação de identidade e das relações sociais. Todo tipo de produção cultural é, portanto, parte de um processo de hegemonia e para ser efetiva deve ser ampla, incluir, formar e ser formada a partir da experiência vivida (WILLIAMS, 1988, p.133).

Artigo recebido em 7 de março de 2017. Aprovado em 3 de julho de 2017. 